\title{
The Electrochemistry of Gold: I The Redox Behaviour of the Metal in Aqueous Media
}

\author{
L D Burke and P F Nugent \\ Chemistry Department, University College Cork, Ireland
}

\begin{abstract}
Gold is frequently regarded as the ideal metal for the investigation of solid electrode behaviour, which in aqueous media is often considered in very simplistic terms as being that of a metal which is highly resistant to dissolution. Gold possesses very weak chemisorbing properties and an extensive double layer region that in the presence of most pure electrolytes is often assumed to be totally free of Faradaic behaviour, and exhibits a monolayer (or $\mathrm{Au}_{2} \mathrm{O}_{3}$ ) oxide formation/removal reaction at quite positive potentials. However, recent investigations have revealed that the electrochemistry of polycrystalline gold in aqueous solution is considerably more complex. Two significantly different types of oxide deposits, monolayer (or $\alpha$ ) and hydrous (or $\beta$ ), may be produced on the metal and the behaviour of the $\beta$-deposit is quite unusual. It is suggested that not only the behaviour of the $\beta$-oxide but, far more important from a practical viewpoint, the catalytic and electrocatalytic behaviour of gold (which will be discussed in more detail in Part II) may be rationalized in terms of the active state (or states) of gold. This active state (frequently present only at very low coverage) reacts in a manner that is quite different from that of stable gold. The nature of the active state of gold deserves far more attention than it has received to date.
\end{abstract}

The importance of surface reactions was highlighted in a recent article by Sachtler (1) who pointed out that $c a$ $17 \%$ of GNP in the US and $c a 25 \%$ in the case of Germany are derived from materials produced by catalytic processes. Most of these processes involve heterogeneous catalysis of gas phase reactions on metal or oxide surfaces. The catalysis of electrode reactions is also important, eg ca 13 million tons (valued at $c a 2.2$ billion dollars) of chlorine gas (2) is produced annually in the US, largely with the aid of electrocatalytically active dimensionally stable $\left.\left(\mathrm{RuO}_{2} / \mathrm{TiO}_{2}\right) / \mathrm{Ti}\right)$ anodes.

The potential in the electrocatalysis field is also quite significant; for example, the development of effective electrocatalysts for the direct methanol/air fucl cell would revolutionise the transport industry. Compared with the internal combustion engine, widely used at present, fuel cells in general offer the prospect of more efficient, cleaner and less noisy energy conversion. Methanol is a much more easily stored fuel than hydrogen for use in mobile energy conversion systems and may, with the development of more cfficient methanol oxidation electrocatalysts, be the system of choice for operation at ambient, or slightly elevated, temperatures in vehicles.

It is generally accepted that reactions at surfaces, eg heterogeneous catalysis, electrocatalysis and corrosion, occur predominantly at active sites (3) and in view of the importance of such reactions one could regard such sites as among the most important entities in chemistry. Yet they are rarely mentioned in Physical Chemistry textbooks, and electrocatalysis is rarely discussed in depth, even in many of the recently published specialized textbooks in the field of electrochemistry. The basic problem in the area seems to be that a clear understanding of the nature, and especially the mode of operation, of such sites is not available (4).

There is an additional problem in the electrocatalysis area in that different modes of operation are assumed to be involved in different types of electrocatalytic processes, viz:

(i) Noble metal electrocatalysis is assumed to involve activated chemisorption (5), viz. 
$\mathrm{HCOOH} \longrightarrow \mathrm{H}^{\mathrm{a}}{ }^{\circ} \mathrm{COOH}=2 \mathrm{H}^{+}+\mathrm{CO}_{2}+2 \mathrm{e}^{-}$

It is generally assumed that in this case the surface metal atoms $(\bullet)$ do not undergo a redox transition.

(ii) Electrocatalysis by solution species is gencrally assumed to involve a cyclic redox process (6), viz:

$$
\begin{aligned}
& M_{\mathrm{aq}}^{z+}=M_{\mathrm{aq}}^{(z+n)+}+n e^{-} \\
& \mathrm{P} \longleftarrow+\mathrm{R} \downarrow
\end{aligned}
$$

$P$ is the oxidation product of solution species $R$ (a reductant) and the dissolved oxidation mediator, $M_{\mathrm{aq}}^{(z+n)_{+}}$, is repeatedly regenerated at the anode surface. A similar scheme may be written for the reduction of a dissolved oxidant $(\mathrm{O})$ in which case the mediator is the reduced form, $M_{\mathrm{aq}}^{z+}$, of the redox couple.

(iii) Electrocatalysis by surface-bonded mediators, eg redox groups or enzymes, is assumed to occur in a similar manner to that outlined in (ii) except that in this case the redox couple remains bonded to the electrode surface (7). An interesting variation of this mode of clectrocatalysis is found in the case of $\mathrm{RuO}_{2}$-based anodes (8) where the mediator is a ruthenate or perruthenate species derived from the surface of the electrode material.

Recent work on noble metal electrochemistry provides the basis of a more unified approach to electrocatalysis. It was demonstrated (9-11) that in many instances the cyclic redox or mediator mode of clectrocatalysis applies also to noble metal electrode processes. The importance of adsorption is not discounted; it is the major (indeed sole) factor in some important processes, eg $\mathrm{H}_{2}$ evolution or ionization, weakening of $\mathrm{C}-\mathrm{H}$ bonds in methanol, etc. However, the mediator route for electrocatalysis seems to be more widespread; apart from providing a common basis for the different types of electrocatalysis it correlates activity for oxidation and reduction for the same electrode system, it applies to both metals and oxides, and rationalizes behaviour in certain important processes, eg removal of inhibiting $\mathrm{CO}_{\text {ads }}$ species, which is a process of considerable practical importance - especially in the fucl cell anode area.

The new approach to noble metal electrocatalysis, sometimes referred to as the IHOAM (Incipient Hydrous Oxide/Adatom Mediator) model, is controversial as:

(i) It stresses the importance of the defect state of surfaces and assumes that, for the same surface, two significantly different types of elcctrochemical responses may be observed - one for high coordination and the other for low coordination surface metal atoms.

(ii) Considerable stress is placed in the new approach on two largely ignored features of noble metal electrochemistry, namely hydrous oxides and active states of the metal.

(iii) In the conventional view of the metal/solution boundary or double layer the surface or boundary is frequently represented as an inert flat plane whereas in the IHOAM approach the metal atoms at the surface are regarded as having a degree of mobility and a range of chemical reactivities; some of these atoms are assumed to undergo electro-oxidation reactions in aqueous media at potentials that are significantly more negative than that normally associated with the onset of regular monolayer oxide formation.

In this, the first of two articles (the second will deal specifically with electrocatalytic processes on gold), an account will be given of the electrochemistry of polycrystalline gold in aqueous media. Since the conventional chemical behaviour of this electrode system has been described earlier by various authors (12-14), attention will be focused here largely on more recent work in which anomalous behaviour was observed. In the present context the behaviour of a metal or oxide is regarded as anomalous if it deviates significantly from that expected from conventional thermodynamic data as summarized, for instance, by Pourbaix (15).

\section{THE CONVENTIONAL BEHAVIOUR OF GOLD}

Gold is the noblest of metals. According to the thermodynamic data for this element (15) gold should be oxidized to the trivalent state, according to the reaction:

$$
\mathrm{Au}+3 \mathrm{H}_{2} \mathrm{O}=\mathrm{Au}_{2} \mathrm{O}_{3}+6 \mathrm{H}^{+}+6 \mathrm{e}
$$

at $1.457 \mathrm{~V}$ if the product is the hydrated oxide (which may be represented as $\mathrm{Au}(\mathrm{OH})_{3}$ or $\mathrm{Au}_{2} \mathrm{O}_{3} \cdot 3 \mathrm{H}_{2} \mathrm{O}$ ), or at $1.511 \mathrm{~V}$ if the product is the anhydrous oxide. The potentials quoted here are standard reversible $\left(\mathrm{E}^{\circ}\right)$ values, calculated using standard chemical potential $\left(\mu^{\circ}\right)$ data, and the aqueous solution is assumed to be free of complexing agents. Most potential values are quoted in this review in terms of the RHE scale, ie with respect to a reversible hydrogen electrode $\left(P_{H_{2}}=\right.$ 
$1.0 \mathrm{~atm})$ in the same solution. This is a convenient scale for use with metal/metal oxide electrodes as, in terms of the conventional bchaviour of such systems, the electrode potential value for a given transition should be $\mathrm{pH}$-independent (the $\mathrm{pH}$-dependence of the working, or oxide, electrode being the same as that of the reference electrode). The fact that significantly different $\mathrm{E} / \mathrm{pH}$ variation is observed, in terms of this RHE scale, for certain oxide/metal (and indeed oxide/oxide) transitions was discussed earlier $(10,16)$.

A typical cyclic voltammogram* recorded for gold in acid is shown in rigure 1 . The most notable feature in the positive swcep is the increase in anodic current,

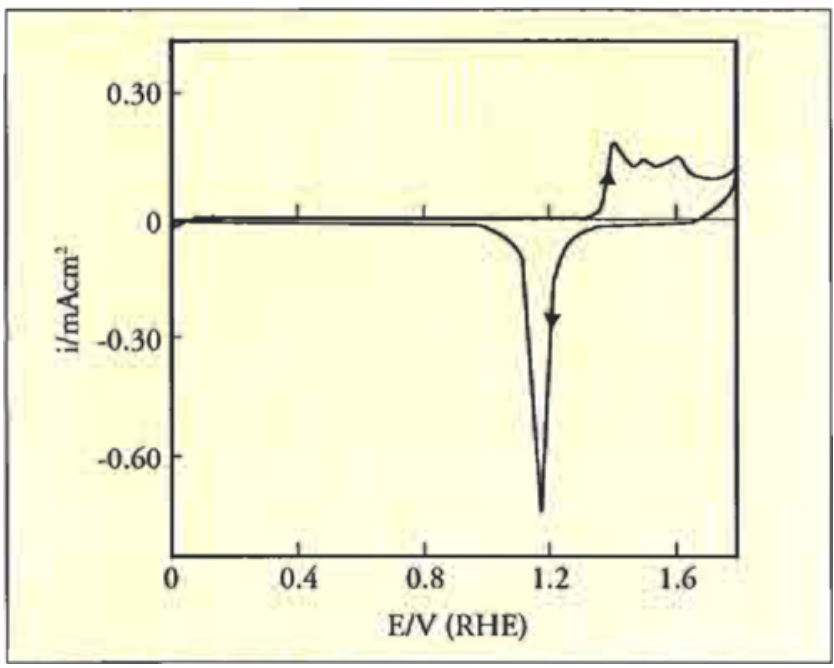

Figure 1 Typical cyclic voltammogram $(0.0$ to $1.80 \mathrm{~V}, 50$ $\left.m V s^{-1}\right)$ recorded for a polycrystalline gold disc electrode in $1.0 \mathrm{~mol} \mathrm{dm}^{-3} \mathrm{H}_{2} \mathrm{SO}_{4}$ at $25^{\circ} \mathrm{C}$

\footnotetext{
*Cyclic voltammetry is a widely used electrochemical technique based on the use of a potentiostat to control the potential (by automatic adjustment of current flow) of the electrode under investigation. In this technique the potential impressed on the electrode is varied in a triangular manner at a presclected sweep rate, $e g 50 \mathrm{mV} \mathrm{s}^{-1}$, beween preselected upper and lower limits. The resulting response is a cyclic voltammogram, it a plot of current versus potential for the forward and reverse sweeps. A large positive potential corresponds to highly oxidizing conditions at the electrode/solution interface and this, depending on the nature of the metal and solution $\mathrm{pH}$, may result in dissolurion of, or oxide formation at, the dectrode surface. The technique is normally used to study the redox behaviour of either solution species or the electrode surface; but the same procedure has been used extensively at Cork to produce and investigate unusual oxide deposits on electrode surfaces (see reference 16 for derails) and to modify, or activate, the outer layers of metal clectrodes. 'The study of the active states of surfaces is a very challenging area of rescarch but the results obtained to date from cyclic voltammetry work are of considerable interest in areas such as heterogeneous catalysis.
}

commencing at $c a 1.36 \mathrm{~V}$, which is due to monolayer (or $\alpha-$ ) oxidc formation at the electrode surface. This process commences at a slightly lower potential than expected on the basis of the $\mathrm{E}^{\circ}$ values quoted here earlier. However, it must be borne in mind that the latter were estimated for the stable bulk metal atoms and it is only for the latter that $\mu^{\circ}(\mathrm{Au})=0$. Surface atoms are inevitably more active; the absence of similar metal neighbours on one side means that they are lacking some of the lattice stabilization energy of their bulk cquivalents and, hence, they tend to oxidize at a lower potential.

The early stage of oxidation of noble metal surfaces is usually discussed in terms of adsorbed hydroxy radical formation (14), viz:

$$
\mathrm{H}_{2} \mathrm{O}=\mathrm{OH}_{\mathrm{ads}}+\mathrm{H}^{+}+\mathrm{e}^{-}
$$

Such an approach may be inadequate in the case of gold as the hydroxy radical is a very high energy species; the $\mathrm{E}^{\circ}$ value for the $\mathrm{H}_{2} \mathrm{O} / \mathrm{OH}$ couple (17) is $2.85 \mathrm{~V}$ (SHE) and gold has an extremely weak chemisorbing capability, eg the coverage of $\mathrm{H}_{\mathrm{ads}}$ on gold at $0.0 \mathrm{~V}$ is only $c a 0.03 \%$ of a monolaycr (12). If the involvement of a hydroxy specics is to be retained, it may be more appropriate to consider the initial oxidation product as some type of metalhydroxy compound, eg $\mathrm{Au}^{\delta+} \ldots \mathrm{OH}^{\delta-}$, the product being a polar covalently-bonded species. The charge associated with further monolayer oxidation does not generally give rise to a single sharp peak above $1.36 \mathrm{~V}$. Instead, the charge in question, for gold in acid, tends to be distributed along a platcau (12) (usually with some minor features evident on the latter) with no major change until oxygen gas evolution commences at $c a 2.0 \mathrm{~V}$ (this latter feature is not shown in Figure 1).

The conditions for complete monolayer oxide formation on gold surfaces are important from a practical viewpoint as it forms the basis of a useful method for determining the true surface arca (or roughness value) of the metal surface. For this purpose, Woods (12) has recommended that the potential of an initially clean gold electrode in $1.0 \mathrm{~mol} \mathrm{dm}^{-3} \mathrm{H}_{2} \mathrm{SO}_{4}$ be held initially at $1.8 \mathrm{~V}$ for $100 \mathrm{sec}$ to achieve monolayer oxide coverage. The charge for monolayer oxide reduction, estimated following the application of a subsequent negative sweep, may be converted to real surface area using the recommended conversion factor of $386 \mu \mathrm{C} \mathrm{cm}^{-2}$ (real area). This is a very convenicnt, though perhaps not very precise, method for the determination of a relatively important electrode parameter. 
A very common feature of monolayer oxide formation/reduction behaviour in the case of the noble metals is hysteresis, $i e$ the difference in the potential range for monolayer oxide formation (positive sweep) as compared with that for monolayer oxide reduction (negative sweep) - see Figure 1. It is generally assumed that hysteresis in this case is due to postelectrochemical processes, ie the product of a given electrochemical reaction undergoes a change after the electron transfer step such that the species, energies and potential range involved in going in one direction are appreciably different to those involved when the process is reversed.

The origin of hysteresis in the monolayer oxide formation/removal processes is usually attributed (14) to gradual changes in the nature of the oxide film. During the growth process dipolar $\left(\mathrm{Au}^{\delta+} . \mathrm{OH}^{\delta-}\right)$ species are produced which, at appreciable coverage, repel one another. Such repulsion raises the energy required to generate additional dipoles; hence, there is an increase in potential with increasing coverage. This is evidently the reason why the monolayer oxide formation response is an extended plateau rather than a sharp peak. The post electrochemical process involved in this case is outlined schematically in Figure 2. Rotation of some of the surface dipoles, a process also referred to as place-exchange, relieves much of the lateral repulsion or stress in the surface layer, resulting in a more stable surface deposit. In the negative sweep the dipole coverage (and any residual stress) is progressively reduced. No electrostatic repulsion barrier is developed in this case and a relative sharp cathodic peak is observed.

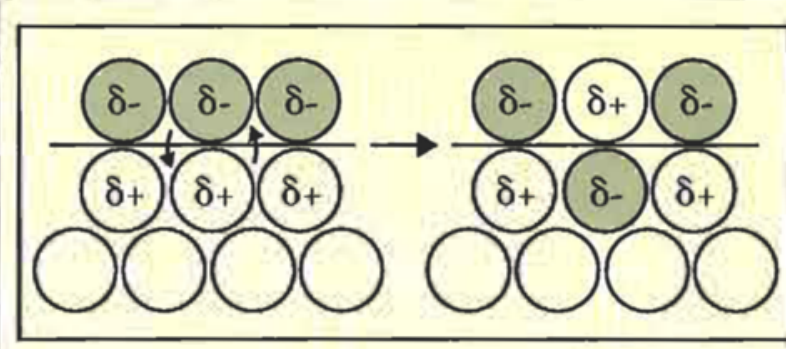

Figure 2 Schematic representation of the postelectrochemical, place-exchange reaction involved in a monolayer oxide formation. Some surface metal atoms (unshaded) switch positions with adsorbed oxygen species (shaded circles). Obviously if these species are charged, as indicated here, the place-exchange reaction leads to a considerable reduction in electrostatic repulsion energy
Therc is an additional factor, related to changes in the activity of the surface metal atoms, that may also contribute to the hysteresis effect. This is the change in activity of surface metal atoms during the course of reaction. Three types (or states of activity) of gold atoms may be considered, namely:

(a) Bulk lattice atoms $\left(\mathrm{Au}^{\circ}\right)$ - these have little relevance to the reaction at the surface;

(b) Regular surface atoms $\left(\mathrm{Au}^{*}\right)$ which are more active than those in the bulk.

(c) Displaced surface atoms $\left(\mathrm{Au}^{* *}\right)$ which are in a state of still higher activity as these are generated initially in a state of unusually low lattice coordination number on reduction of the partially place-exchanged surface oxide.

Atoms of type (c) are assumed to undergo spontaneous rapid alteration to the state represented here by (b). The different states in question here should not be viewed in a very rigorous manner as, in the first instance, solid surfaces tend to be heterogeneous (it is more a qucstion of the spread and occupancy of different energy states).

According to this approach hysteresis may be considered in terms of the following scheme, viz:

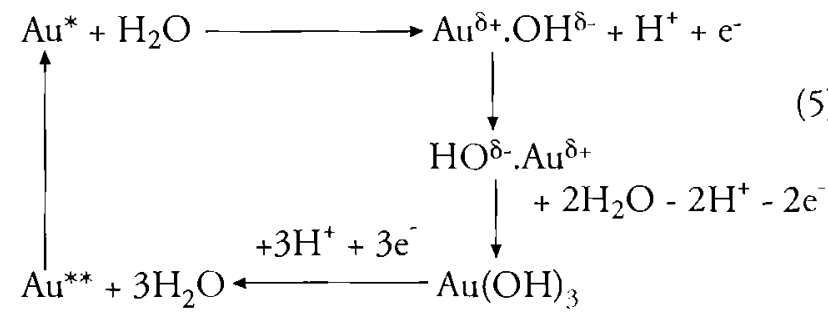

The two post-electrochemical steps are represented here by the vertical arrows. The scheme also highlights another complication in the case of the positive sweep, namcly, the conversion of surface dipoles, $\mathrm{Au}^{\delta+} \cdot \mathrm{OH}^{\delta-}$, to a more regular oxide species, ie formation of species such as $\mathrm{Au}(\mathrm{OH})_{3}$, or $\mathrm{Au}_{2} \mathrm{O}_{3}$.

Examples of cyclic voltammograms recorded for gold in base are shown in Figure 3. The onset potential for the initiation of monolayer oxide growth in this case, $c a 1.25 \mathrm{~V}$, is significantly lower than in acid (18). An unusual feature in the response for gold in base is the large anodic peak in the positive sweep (which has no cathodic counterpart on the subsequent negative sweep) extending over the range of $c a 1.6$ to $2.0 \mathrm{~V}$ - see Figure $3(\mathrm{~b})$. The process giving rise to this response is assumed to be oxygen gas evolution catalysed in a transient manner by some type of nascent hydrous gold oxide species formed at the monolayer oxide/aqueous solution interface (19). The transitory 
nature of the activity in this region was attributed to conversion of the active gold species to a less active deposit which may well be conventional gold hydrous oxide material. Regular oxygen gas evolution on gold in base (as in acid) occurs vigorously only above $c a$ $2.0 \mathrm{~V}$. The behaviour shown here on the negative sweep over the range 2.1 to $1.6 \mathrm{~V}$ (see Figure 3(b)) may well be a better reflection of the steady state oxygen gas evolution activity of gold in base than that shown in the corresponding region of the positive sweep where the influence of transient activity is quite marked.

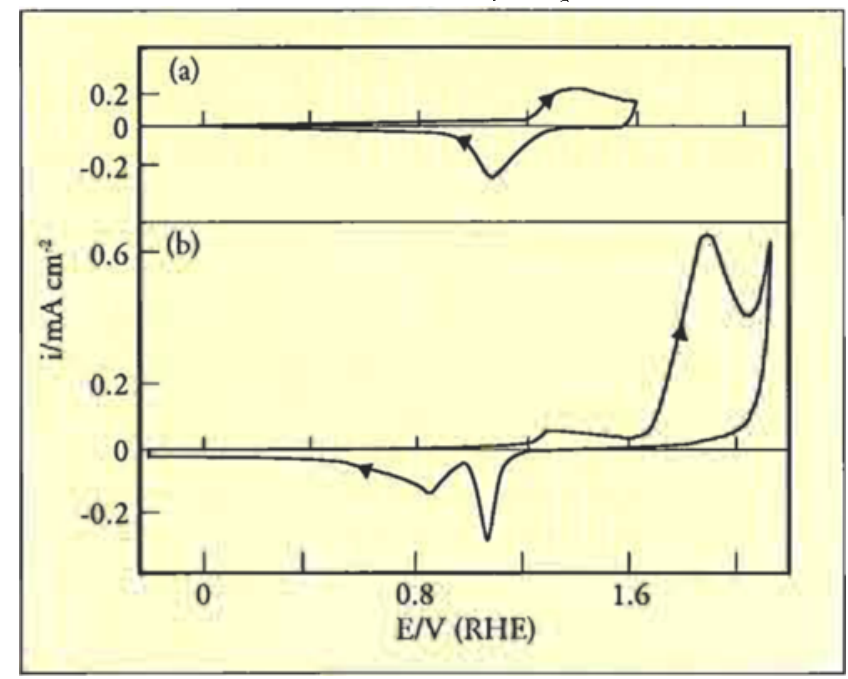

Figure 3 Typical cyclic voltammograms for a polycrystalline gold electrode in $1.0 \mathrm{~mol} \mathrm{dm}^{-3}$ $\mathrm{NaOH}$ at $25^{\circ} \mathrm{C}$ : (a) 0.0 to $1.60 \mathrm{~V}$ at 50 $\mathrm{mVs}^{-1}$; (b) -0.2 to $2.1 \mathrm{~V}$ at $10 \mathrm{mVs}^{-1}$

An interesting feature of the negative sweep in Figure 3(b) is the appearance of a second cathodic peak at $c a .0 .85 \mathrm{~V}$. The monolayer oxide reduction peak was observed in this case at $c a 1.07 \mathrm{~V}$ and the subsequent peak is assumed to be due to reduction of hydrous gold oxide species formed on the gold surface at the upper end of the cycle. The growth and subsequent reduction of such hydrous oxide deposits were discussed in some depth in earlier reviews $(16,20)$.

\section{ANOMALOUS BEHAVIOUR OF GOLD}

\section{Hydrous Oxide}

In terms of gross departure from behaviour expected on the basis of thermodynamic data, two aspects of the electrochemistry of gold merit special consideration, namely, (i) the hydrous oxide electrochemistry of gold, and (ii) the premonolayer oxidation of gold.

Multilayer hydrous oxide deposits are readily produced on gold in aqueous solution by either $\mathrm{dc}$ polarization (21) at potentials within the oxygen gas evolution region $(\mathrm{E} \geq 2.0 \mathrm{~V})$ or by repetitive potential cycling (22) or pulsing (23). Such growth occurs most readily in acid solution and the product obtained is a rather amorphous, hydrated $\mathrm{Au}(\mathrm{III})$ oxide. As pointed out here earlier, thermodynamic data suggest that this matcrial should be produced at ca $1.46 \mathrm{~V}$; however, at the latter value most of the gold surface is already coated with a monolayer oxide $(\alpha)$ film which evidently passivates the surface with regard to hydrous $(\beta)$ oxide growth. The $\alpha$ deposit is assumed to be an adherent layer of compact material through which $\mathrm{Au}^{3+}$ ion migration is quite slow. Both oxygen gas evolution and hydrous oxide growth may involve formation of an unstable (15) Au(IV) oxide species as outlined in the following scheme, viz:

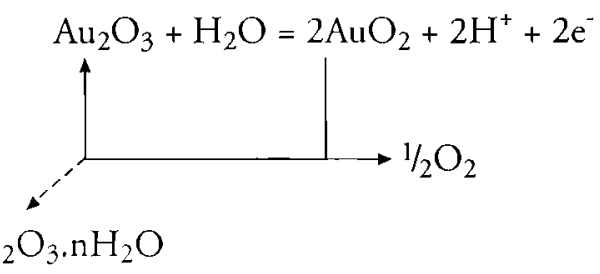

According to this scheme some of the monolayer oxide material is converted, at $\mathrm{E} \geq 2.0 \mathrm{~V}$ to gold peroxide species which decomposes to yield oxygen gas. This process continues in a cyclic manner, resulting also (possibly as a side reaction) in the generation of an increasing thickness of the $\beta$-material. There are other possibilities, eg oxygen evolution on the $\alpha$-oxide may result in the generation of flaws in the latter through which gold cations emerge to form the $\beta$-oxide, ie the growth of the latter may proceed without the intervention of any other oxide species.

The use of repetitive potential cycling as a technique for producing hydrous oxide deposits has already been discussed (16). At the upper limit of each cycle some metal atoms are displaced in accordance with the scheme shown here in Figure 2. Reduction of much of the $\alpha$-film at the lower limit of the negative sweep results in the generation of active (low lattice coordination) surface metal atoms which react spontaneously with water molecules to yield some $\beta$ material. Important requirements in this case are that (i) the $\beta$-material must be of a low density or porous in nature to allow access of water to the surface of the $\alpha$ oxide where the hydrous oxide formation is assumed to 
occur, and (ii) the lower limit of the oxide growth cycle must be such that much of the $\alpha$-, but little if any of the $\beta$-, oxide is reduced.

The responses recorded during the course of a ncgative swecp for a hydrous oxide-coated gold electrode are complicated by the fact that the behaviour observed is strongly influenced by factors such as the thickness of the deposit and the $\mathrm{pH}$ of the solution. In most cases the interface in question contains both the $\alpha$-(monolayer) and $\beta$ - (multilayer) materials arranged in the following manner: gold $/ \alpha-$ oxide/ $\beta$-oxide/aqueous solution. Generally the first cathodic response is that due to reduction of the $\alpha$ oxide and this usually results in a peak with a potential maximum $\left(\mathrm{E}_{\mathrm{p}}\right)$ in the region of $c a 1.0 \mathrm{~V}$ (the observed value varies (24) with factors such as oxide formation potential, oxide coverage, sweep rate, etc). With thin oxide films in acid solution (21) the reduction of the $\beta$-oxide deposit gives rise to a single peak which overlaps with the monolayer oxide reduction peak. Similar behaviour was observed for the reduction of relatively thin oxide films on gold in base, except that in this case a clear separation, in terms of potential, is observed between the two peaks. The $\alpha$-oxide reduction occurs again at $c a 1.0 \mathrm{~V}$ (with a minor shift to lower values of $\mathrm{E}_{\mathrm{p}}$ with increasing $\mathrm{pH}$ ) but the maximum of the $\beta$-oxide reduction peak occurs (21) at $c a 0.65 \mathrm{~V}$. Such a drop in potential, $c a-0.5(2.3 \mathrm{RT} / \mathrm{F})$ $\mathrm{V}$ per $\mathrm{pH}$ unit, on changing from acid to base, is quite common for hydrous oxide systems. Similar behaviour, sometimes referred to as a super-Nernstian shift, has been obscrved even in the case of highly reversible oxide/oxide transitions (16), eg those involving $\mathrm{Ir}, \mathrm{Rh}$, $\mathrm{Fe}$ and $\mathrm{Ni}$ ions.

There are complications in the interpretation of super-Nernstian $\mathrm{E} / \mathrm{pH}$ shifts in the case of gold in that (i) the structure, composition and state of charge of the oxyspecies are unknown, and (ii) the overall reduction step occurs in an irreversible manner. It has been suggested (24) that the behaviour in question may be interpreted in terms of the following scheme (this describes the reaction in terms of a monomer unit of the oxide polymer), viz:

$$
\begin{aligned}
& \mathrm{Au}_{2}(\mathrm{OH})^{3-}{ }_{9}+9 \mathrm{H}^{+}+6 \mathrm{e}^{-}=2 \mathrm{Au}^{* *}+9 \mathrm{H}_{2} \mathrm{O} \text { (fast) } \\
& 2 \mathrm{Au}^{* *} \longrightarrow 2 \mathrm{Au}^{*}
\end{aligned}
$$

The first step is assumed to be rapid and reversible and this process may be treated in a Nernstian manner. Application of the Nernst equation to Equation 7 yields:
$E=E^{\circ}+\frac{2.3 R^{\top} T}{6 F} \log a_{o x^{-}} \frac{2.3 R T}{3 F} \log a_{A t^{*}}-1.5\left(\frac{2.3 R T}{F}\right) p H$

( $a_{o x}$ represents the activity of the oxyspecies). According to the latter equation the equilibrium potential for the process shown in Equation 7 should decrease by $c a-1.5 \quad(2.3 \mathrm{RT} / \mathrm{F}) \mathrm{V} / \mathrm{pH}$ unit $(\mathrm{pH}-$ independent scale) or $c a-0.5(2.3 \mathrm{RT} / \mathrm{F}) \mathrm{V} / \mathrm{pH}$ unit (RHE scale). An obvious objection to this approach is that the reduced form of the couple $\left(\mathrm{Au}^{* *}\right)$ is not at constant activity. Howcver, the same E/pH trend is observed for intermediate (oxide/oxide) transitions in the case of other, redox active, hydrous oxide systems (16) where the decay of metal atom activity is clearly not involved, ie super-Nernstian $\mathrm{E} / \mathrm{pH}$ shifts are a widespread feature with redox-active hydrous oxide deposits.

The $\beta$-oxide material exists outside the metal surface, ie it is clearly not an adsorbed state. An example of materials that may be similar to the $\beta$-oxide are certain soil colloids (25) such as layered silica clays and hydrous oxides of iron and aluminium. In most of these colloids the oxycation framework bears a negative charge with ion-exchangeable cations, eg $\mathrm{H}_{3} \mathrm{O}^{+}, \mathrm{Na}^{+}$, $\mathrm{Ca}^{2+}$, present as counterions in the intercalated water. The assumption here is that the gold oxide and aqueous components are intermingled in the $\beta$-layer. The accumulation of negative charge on the oxide strands or layers in the $\beta$-material may be viewed in terms of a hydrolysis effect (26), ie as a combination of excess hydroxide ion coordination and loss of protons from coordinated water molecules, viz.

$\mathrm{HO}^{-} \mathrm{Au}^{3+}{ }_{-} \mathrm{OH}_{2} \stackrel{+\mathrm{OH}^{-}}{\longrightarrow}-\mathrm{Au}^{3+} \mathrm{OH}_{2} \stackrel{-\mathrm{H}^{+}}{\longrightarrow}-\mathrm{Au}^{3+}-\mathrm{OH}^{-}$

at highly charged cation $\left(\mathrm{Au}^{3+}\right)$ sites. The involvement of super-Nernstian $\mathrm{E} / \mathrm{pH}$ shift effects in the electrocatalytic behaviour of gold has already been demonstrated (27).

Recent reinvestigation of hydrous oxide growth on gold under repetitive potential cycling conditions (28) have shown that the behaviour of these oxides is significantly more complex than assumed earlier. With thicker oxide deposits in acid solution four oxide reduction peaks were noted, Figure $4(\mathrm{a})$. The $\mathrm{E}_{\mathrm{p}}$ values and oxide assignments are as follows:- $\mathrm{C}_{1}, 1.1 \mathrm{~V}$ (monolayer oxide); $\mathrm{C}_{2}^{\prime}$ and $\mathrm{C}_{2}, 0.97$ and $0.94 \mathrm{~V}$ (the oxide involved, $\mathrm{HO} 1$, is assumed to contain two slightly different components); $\mathrm{C}_{3}, 0.73 \mathrm{~V}$ ( $\left.\mathrm{HO} 2\right) ; \mathrm{C}_{4}$, $0.58 \mathrm{~V}$ (HO3). It may be noted that evidence of a 
similar nature was obtained recently for the presence of threc distinct components in hydrous oxide films grown on Pt in acid (29).

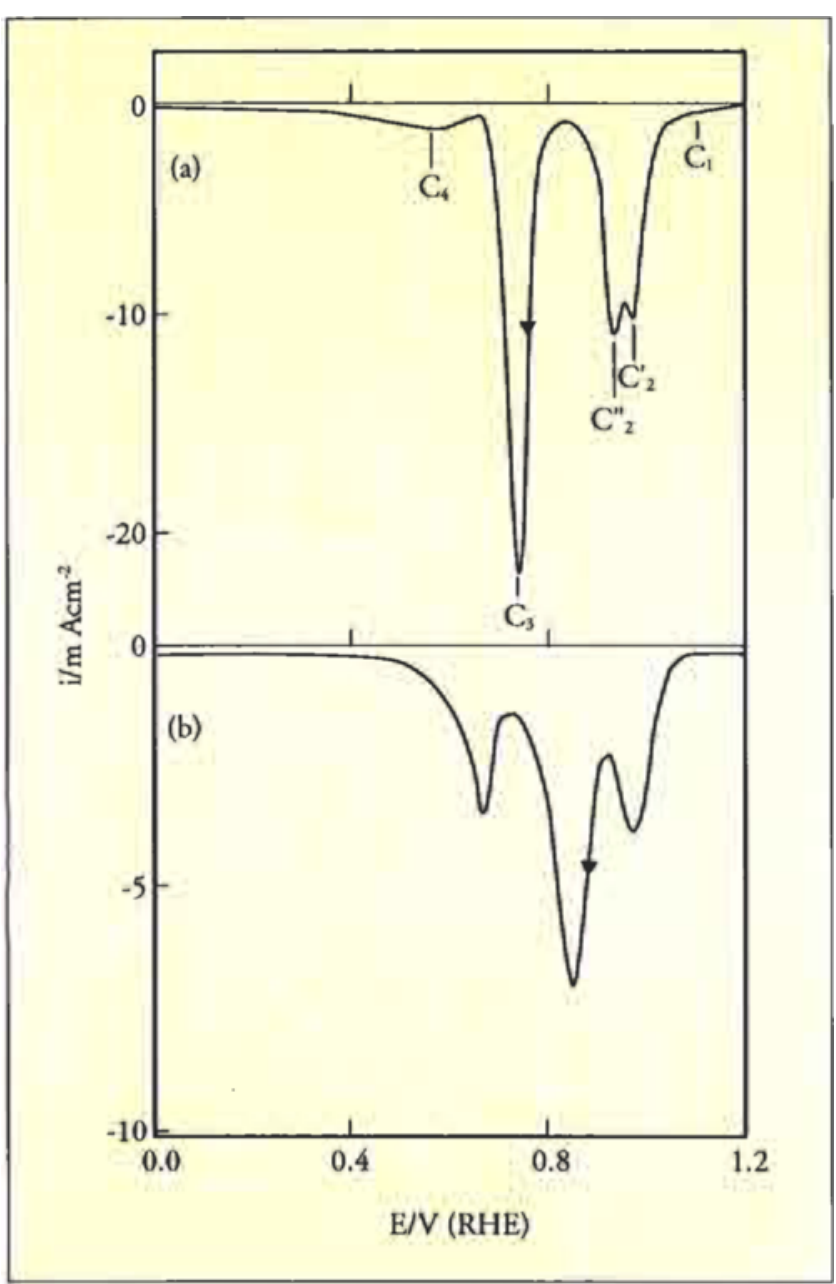

Figure 4 Reduction profiles, 1.20 to $0.0 \mathrm{Vat} 2 \mathrm{mV} \mathrm{s}^{-1}$, for multilayer bydrous oxide films grown on a mildly abraded gold wire electrode by repetitive potential cycling (oxide growth conditions: -1.0 $\times 10^{t}$ cycles between 0.90 and $2.40 \mathrm{~V}$ at 50 $V s^{-1}$ in $1.0 \mathrm{~mol} \mathrm{dm}^{-3} \mathrm{H}_{2} \mathrm{SO}_{4}$ at (a) $25^{\circ} \mathrm{C}$, and (b) $35^{\circ} \mathrm{C}$

One of the interesting features that emerged from the recent investigation (and which explains why the complexity of the system was not appreciated earlier) was that some of the components involved, especially $\mathrm{HO} 2$, are produced only after an extended number ( $c a$ 2500 ) of oxide growth cycles, Figure 5. For films of constant thickness the charge for reduction of the various oxide components was virtually independent of sweep rate $\left(5-100 \mathrm{mV} \mathrm{s}^{-1}\right)$. The peak potential $\left(E_{p}\right)$ values decreased, though not dramatically, while the peak current ( $\left.i_{p}\right)$ valucs increased linearly, with increasing oxide reduction swcep rate. Such behaviour indicates that the oxide reduction processes (especially for $\mathrm{HO} 1$ and $\mathrm{HO} 2$ - the peak for $\mathrm{HO}_{3}$ was quite broad at fast, $>5 \mathrm{mV} \mathrm{s}^{-1}$, swcep rates) occur rapidly, ie in a quasi-reversible manner ( $c f$ Equations 7 and 8).

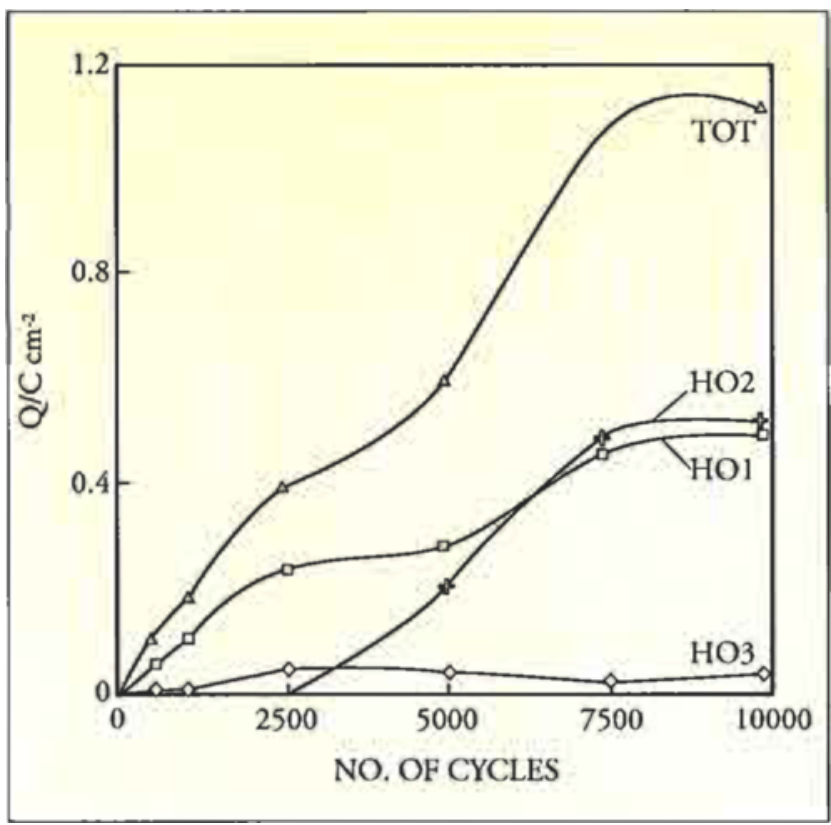

Figure 5 Variation of the charge for bydrous oxide reduction as a function of the number of oxide growth cycles. The conditions used (apart from the number of (ycles) are as specified in Figure $4(a)$. The latter diagram also shows the oxide peak assignments:- $\mathrm{C}_{2}^{\prime}+\mathrm{C}_{2}^{\prime \prime}, \mathrm{HOI} ; \mathrm{C}_{3}$, $\mathrm{HO} 2 ; \mathrm{C}_{4}, \mathrm{HO} 3$

The reduction behaviour of thick hydrous oxide films on gold in base is much more complex than that observed for gold in acid. Conditions for producing such films in base, using the repetitive potential cycling technique, were investigated by Burke and Hopkins (22) who observed in some instances oxide reduction peaks with a maximum $\left(\mathrm{E}_{\mathrm{p}}\right)$ at $c a 0.2 \mathrm{~V}$. More recent work (30), an example from which is outlined here in Figure 6 , has yielded a behaviour pattern that is even more unusual as a major portion of the charge required for oxide reduction at a very slow sweep rate was observed in the region between $c a-0.1$ to $-0.3 \mathrm{~V}$. With an organic base electrolyte the extent of reduction of a gold hydrous oxide film in the negative sweep at $\mathrm{E}>0.0 \mathrm{~V}$ was quite small. The main oxide reduction response occurred in this case (at $10 \mathrm{mV} \mathrm{s}^{-1}$, Figure 7) only at $\mathrm{E}<-0.3 \mathrm{~V}$. 


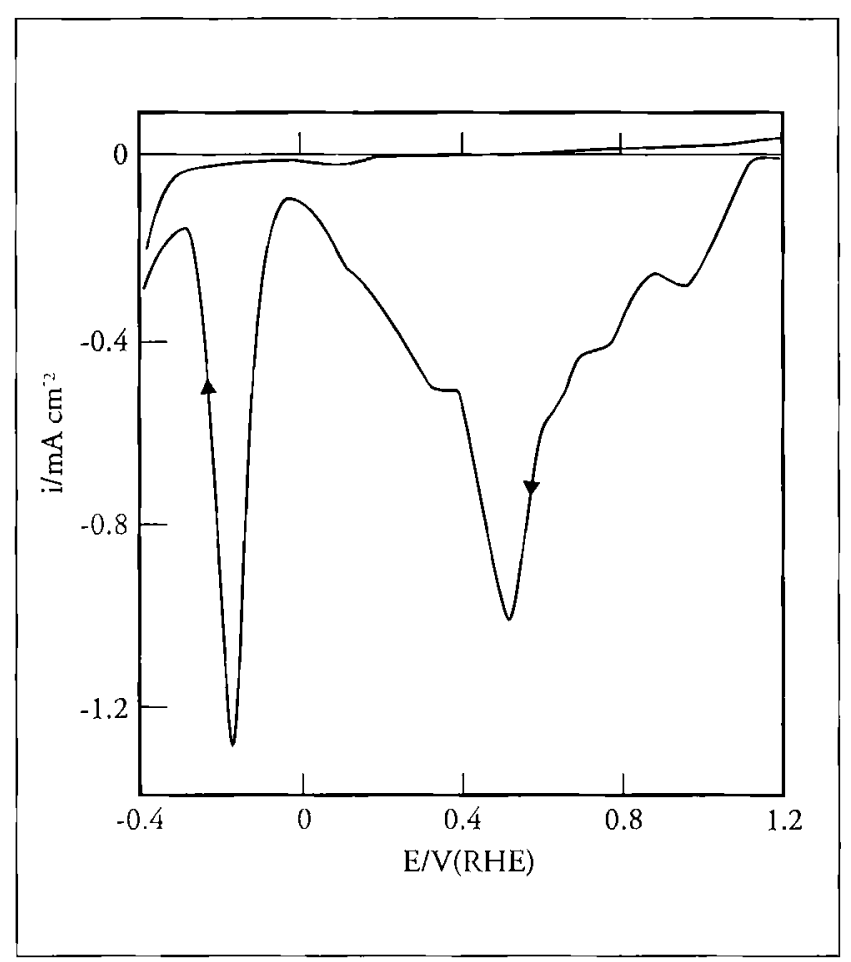

Figure 6 Reduction profile, 1.2 to $-0.4 \mathrm{~V}$ at $2.0 \mathrm{mV} \mathrm{s}^{-1}$ for a thick oxide film grown on a pre-abraded gold wire electrode in $1.0 \mathrm{~mol} \mathrm{dm}^{-3} \mathrm{NaOH}$ at $25^{\circ} \mathrm{C}$ (the dashed line shows the subsequent positive sweep. The oxide deposit was produced in-situ by potential cycling, 0.75 to $2.40 \mathrm{~V}$ at $50 \mathrm{Vs}^{-1}, 6364$ cycles

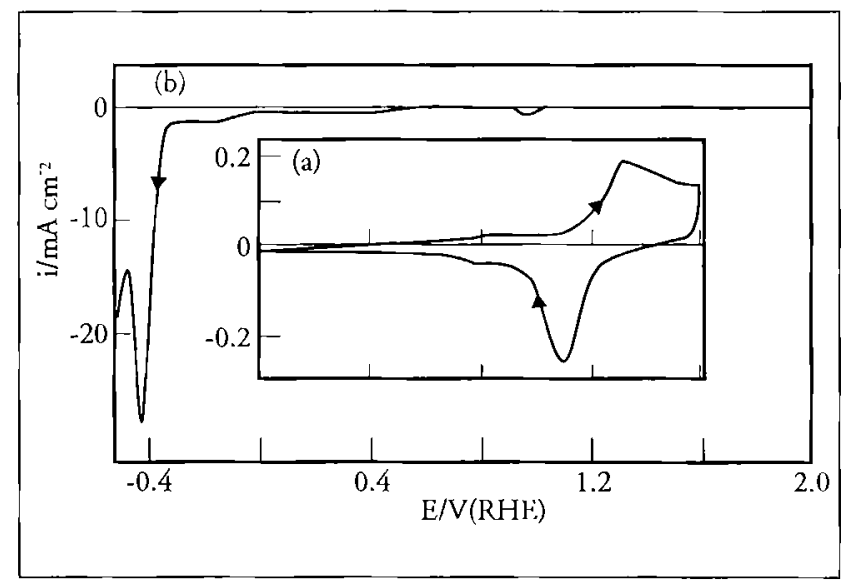

Figure 7 Reduction profile, 1.2 to $-0.5 \mathrm{Vat} 10 \mathrm{mVs}^{-1}$ for a thick oxide (produced in-situ by $d c$ polarization at $2.3 \mathrm{~V}$ for $90 \mathrm{~min}$ ) in $1.0 \mathrm{~mol}$ $d m^{-3}\left(\mathrm{C}_{2} \mathrm{H}_{5}\right)_{4} \mathrm{NOH}$ at $25^{\circ} \mathrm{C}$. The inset shows a cyclic voltammogram, 0.0 to $1.6 \mathrm{~V}$ at 50 $m V s^{-1}$, for the same electrode in the absence of the hydrous oxide deposit
Apart from establishing the basic electrochemistry of these gold hydrous oxide systems in aqueous media, very little other work has been devoted to this topic; hence only basic ideas can be outlined here. The reactions involved, cven in acid solution, obviously do not occur under ideal thermodynamically reversible conditions, ie there is significant cathodic overpotential involved and there are various possible contributions to the latter. It seems unlikely that the monolayer oxide deposit acts as a barrier to $\beta$-oxide reduction, especially in base where (in the case of thin films) the two cathodic peaks in the negative sweep are quite far apart. The $\beta$-layer may be regarded as a semi-rigid, amorphous deposit and since reduction probably occurs at the oxide/metal interface there may well be difficulty in maintaining contact between the metal surface and much of the nearby oxide deposit when the latter is undergoing reduction. Oxides and hydroxides are generally more reactive (eg more prone to dissolution) in acid solution. It was pointed out earlier $(21,24)$ that the activity of $\mathrm{Au}^{3+}$ cations, existing in a gel network of $\mathrm{OH}^{-}$and $\mathrm{OH}_{2}$ species in the $\beta$-layer, is influenced by the $\mathrm{OH}^{-}$ion activity in the bulk solution. This approach, developed originally to rationalize the super-Nernstian E/pH effect mentioned earlier, highlights one important contribution to the marked overpotential observed in the case of the $\beta$-oxide reduction in base, as compared to acid.

Another major factor in the oxide film reduction process is a combination of lattice stabilization energy and particle size effect at the gold surface. There is evidence from Scanning Tunnelling Microscopy (STM) (31) that discharge of metal ions from solution occurs most readily at ledge sites on the surface. Metal ions in the $\beta$-layer (especially in base where the layer is more stable) are less free to move to such sites; there may, for instance, be some preliminary discharge at such sites, followed by localized loss of contact. Then, over much of the surface, oxide reduction may have to occur under conditions where the metal atoms are produced in a poorly lattice stabilized, active form. Small clusters of atoms formed at the interface also constitute a high energy state of the metal - the inverse relationship between cluster radius and overpotential (32).

$$
r_{\mathrm{c}}=-\frac{2 M \gamma}{n F \eta \rho}
$$

Equation 11 is well known from electrochemical nucleation theory $\left(r_{c}\right.$ is the critical radius of the cluster, $M$ is the molar mass of the metal, $\rho$ is the 
density of the cluster which has a surface tension or surface energy $\gamma$ ). Since the cluster is unstable (or cannot form) until $r>r_{c}$ the driving force or overpotential $(\eta)$ must be increased (this also has the effect of reducing the nucleation barrier energy and $r_{c}$ value) until oxide reduction occurs at a rapid rate. The unusually high overpotential observed in some instances in alkaline solution, Figures 6 and 7, may reflect a combination of very low $\mathrm{Au}^{3+}$ activity (the oxide matrix being more stable in base) and high gold atom activity. The unusually low reduction potentials observed in the presencc of the tetralkylammonium hydroxide electrolyte, Figure 7, may reflect the effect of adsorption of $\mathrm{NR}_{4}{ }^{+}$ions on either the gold surface or the initially produced adatoms (32) - this may result in inhibition of cluster growth, an unusually high metal activity and a very low reduction potential. Another possibility is that accumulation of hydrophobic cations at the interface affects either the oxide polymer or some pre-electrochemical stcp (perhaps depolymerization).

The presence of several peaks in the oxide reduction process, sce Figure 4, may be due to the existence of more than one type of hydrous oxide species or more than one state of activity of the freshly produced gold atoms - the influence of activity, in Nernstian terms, is evident from Equation 9. Whilc the precise origin of such behaviour is unknown, the phenomenon is of significant importance as the electrocatalytic behaviour of gold (33) (and indeed platinum (11)) is also assumed to involve the reaction of two distinct surface oxide mediator species.

\section{Pre-Monolayer Oxidation}

Gold is frequently regarded as the ideal solid electrode system for fundamental investigations in electrochemistry as, in the absence of redox active species in the aqueous phase, the system apparently exhibits only non-Faradaic (or double layer) behaviour over the range of about 0 to $1.3 \mathrm{~V}$ in acid or 0 to $1.2 \mathrm{~V}$ in base. However, as pointed out by Woods (12), there have been repeated assertions that Faradaic behaviour due to the formation of oxyspecies at the gold surface occur well within the double layer region. Such reports were usually dismissed, the effects in question being attributed to the presence of impurities either on the metal surface or in the bulk solution.

More convincing evidence for the formation of oxide spccies in the double layer region of gold, ie premonolayer oxidation of the latter, has been obtained more recently with the aid of optical/spectroscopic techniques. Nguyen Van Huong and co-workers (34), on the basis of electrochemical and spectroscopic data, postulated in 1980 that some type of oxyspecies was formed in the double layer region (to a coverage of $10-20 \%$ of the surface) on gold in base. In the following year Watanabe and Gerischer (35) postulated, on the basis of photochemical data, that gold in acid exhibited premonolayer oxidation extending over the potential range 0.85 to $1.35 \mathrm{~V}$. Desilvestro and Weaver (36), using Surface Enhanced Raman Spectroscopy (SERS), established that for gold in base the product of premonolayer oxidation was a hydroxy species, and, quite importantly, one that was of different character to the species involved in the regular monolayer oxidation reaction. Hutton and Williams (37), on the basis of scanning laser microscopy data, also claimed that some oxidation of the gold surface occurred prior to regular monolayer oxide formation; furthermore, they found that the incipient oxide involved was exceptionally stable - only being removed by prolonged evolution of hydrogen gas.

Claims based on electrochemical data for premonolayer oxidation in the double layer region continue to appear. Of particular interest is the procedure used by Kirk and co-workers (38) who used a relatively low upper sweep limit. By avoiding the large response for the monolayer oxide formation/removal process, and using fast sweep rates and high recorder sensitivities, they observed marked Faradaic responses in the double-layer region for gold in base. Other authors who have reported unusual responses attributable to the formation of oxyspecies on gold in aqueous media include Conway and coworkers (for both acid (39-41) and base (42)), and one of the present authors $(19,43)$. Firther data obtained using non-electrochemical techniques that support the premonolayer oxidation approach include the radioactive tracer work of Horanyi and Rizmayer (44), and the Quartz Crystal Microbalance (QCM) investigations of Gordon and Johnson (45) (these two groups worked with gold in base and acid, respectively). More recent (QCM data for gold in base by Kautek and co-workers (46) were also interpreted in terms of premonolayer oxidation behaviour.

The essential point seems to be that nearly all metal surfaces contain defects which from a catalytic or electrocatalytic viewpoint may be considered as the sites at which catalytic and electrocatalytic reactions occur (11). The metal atoms at such sites are low coordination species - this was established recently by Ertl and co-workers (47), using STM, in the case of nitric oxide decomposition on ruthenium single crystal plane surfaces. The low lattice stabilization energy of 
the active site metal atoms means that these atoms are significantly more electronegative than their bulk lattice equivalents, ie these protruding metal atoms oxidize at unusually low potentials.

In general, very little is known about active site behaviour (4). Apart from the fact that the surface coverage of such sites is low, the material or atoms present at such sites constitute an active state of the metal and the atoms involved are (i) far from being in thermodynamic equilibrium with the bulk phase, and (ii) apparently exhibit an unusual mode of electrochemical behaviour (11). It is assumed that adatoms and small clusters of same at the surface are oxidized in aqueous media to form incipient hydrous oxide (rather than $\mathrm{OH}_{\text {ads }}$-type) species. It was pointed out earlier (48) that whereas the electrocatalytic activity of metals is usually quite marked in the double layer region (due to the involvement of low coverage incipient oxides), the onset of monolayer oxide formation frequently results in inhibition.

It is known, eg from the work of Henglein (49), that with extremely small metal particles the redox potential of the metal shifts in the negative direction with decreasing particle size; this effect is quite dramatic when the number of metal atoms involved is extremely small. The same concept is employed in the IHOAM approach (11) except that the active metal atoms, instead of being in a free particle, are attached to the surface of the electrode. Evidence supporting the idea of active states of metals is provided by the work of Parmigiani and co-workers (50) who found that supported platinum microclusters also undergo anomalous oxidation, ie they react with oxygen under far milder conditions than the bulk metal. Suggs and Bard (51) have emphasized that microscopic potentials of metal atoms at different surface sites are not the same; however, they also indicated that there is no method of determining the surface energetics of different sites (the standard $\mathrm{E}^{\circ}$ value for a metal represents an averaging of values over atoms at different sites). Pre-monolayer responses, as observed in cyclic voltammetry experiments (43), may be regarded as a preliminary attempt to determine the redox behaviour of active surface atoms which play a vital role in the catalysis of many surface and interfacial reactions.

\section{CONCLUSIONS}

From the work described in this, the first of two articles reviewing the electrochemistry of gold, we have described recent work on the behaviour of polycrystalline gold in acidic and basic aqueous media. Two significantly different types of oxide deposits may be produced on the metal and the conditions under which these are formed and their properties have been considered in Part I. In Part II the catalytic, and particularly the electrocatalytic, behaviour of gold will be considered in relation to the results described above. The special properties of gold, as revealed in these articles, will undoubtedly lead to further investigations and could lead to new applications.

\section{ABOUT THE AUTHORS}

Lawrence Declan Burke received his BSc and MSc from University College Cork in 1959 and 1961, respectively, and a PhD in 1964 from Queen's University Belfast where he worked with F.A. Lewis on the palladium hydride system. He spent a year as an Alexander von Humbolt Fellow in Karlsruhe University, Germany, where he worked on solid statc electrochemistry with Professor Hans Rickert. Since returning to Cork he has been involved in an extensive investigation of the electrochemistry of metals, oxides and especially hydrous oxides. This work, which is concerned largely with the unusual or non-ideal behaviour of these systems, is relevant to such areas as electrocatalysis, electrochromic systems, electroless deposition of metals, etc. Professor Burke was awarded Fellowship of the Electrochemical Society in 1995.

Patrick Francis Nugcnt received his BSc degree in chemistry from University College Cork in 1992. He is currently completing his $\mathrm{PhD}$ degree on the electrochemistry of gold in aqueous media.

\section{REFERENCES}

1 W.M.H. Sachtler, Ber. Bunsenges. Phys. Chem., 1995, 99, 1295

2 G. Pillay and C.P. Chen, J. Electrochem. Soc., $1996,143,3410$

3 G.M. Schwab in 'Catalysis - Science and Technology', Vol. 2, ed. J.R. Anderson and M. Boudart, Springer-Verlag, Berlin, 1981, p.4

4 T: Wolfram and S. Ellialtioglu in 'Theory of Chemisorption', ed. J.R. Smith, Springer-Verlag, Berlin, 1980, p.150

5 D. Pletcher, J. Appl. Electrochem., 1984, 14, 403

6 J.C. Farmer, in 'Environmental Oriented Electrochemistry', ed. C.A.C. Sequeira, Elsevier, Amsterdam, 1994, p.565 
7 R.D. Rochlin and R.W. Murray, J. Phys. Chem., $1981,85,2104$

8 L.D. Burke and J.F. Healy, J. Electroanal. Chem., $1981,124,327$

9 L.D. Burke and T.G. Ryan, J. Appl. Electrochem., 1990, 20, 1053

10 L.D. Burke, Electrochim. Acta, 1994, 39, 1841

11 L.D. Burke and P.F. Nugent, Electrochim. Acta, 1997, 42, 399

12 R. Woods, in 'Electroanalytical Chemistry', Vol. 9, ed. A.J. Bard, Marcel Dekker, New York, 1976, p. 1

13 G. Belanger and A.K. Vijh, in 'Oxides and Oxide Films', Vol. 5, ed. A.K. Vijh, Marcel Dekker, New York, 1977, p.1

14 B.E. Conway, in 'Progress in Surface Science', Vol. 49, ed. S.G. Davidson, Pergamon, New York, 1995, p.331

15 M. Pourbaix, in 'Atlas of Electrochemical Equilibria in Aqueous Solutions', Pergamon, Oxford, 1966, p.399

16 L.D. Burke and M.E.G. Lyons, in 'Modern Aspects of Electrochemistry' No.18, ed. R.E. White, J.O'M. Bockris and B.E. Conway, Plenum Press, New York, 1986, p.169

17 G. Milazzo and S. Caroli, 'Tables of Standard Electrode Potentials', John Wiley, Chichester, 1978, p. 229

18 L.D. Burke, M.M. MacCarthy and M.B.C. Roche, J. Electroanal. Chem., 1984, 167, 291

19 L.D. Burke, V.J. Cunnane and B.H. Lee, J. Electrochem. Soc., 1992, 139, 399

20 L.D. Burke, D.T. Buckley and A.J. Morrissey, Analyst, 1994, 119, 841

21 L.D. Burke and M. McRann, J. Electroanal. Chem., 1981, 125, 387

22 L.D. Burke and G.P. Hopkins, J. Appl. Electrochem., 1984, 14, 679

23 A.C. Chialvo, W.E. Triaca and A.J. Arvia, J. Electroanal. Chem., 1984, 171, 303

24 L.D. Burke, M.E. Lyons and D.P. Whelan, J. Electroanal.Chem., 1982, 139, 131

25 N.C. Brady, 'The Nature and Properties of Soils', 10th Edition, Macmillan, New York, 1990, p. 177

26 L.D. Burke, M.E. Lyons, E.J.M. O'Sullivan and D.P. Whelan, J. Electroanal. Chem., $1981,122,403$

27 L.D. Burke and K.J. O'Dwyer, Electrochirn. Acta, $1989,34,1659$
28 L.D. Burke and P.F. Nugent, to be published

29 L.D. Burke and A.J. Morrissey, J. Appl. Electrochem., 1996, 26, 593

30 L.D. Burke and J.M. Moran, to be published

31 R.J. Nichols, D.M. Kolb and R.J. Behm, J. Electroanal. Chem., 1991, 313, 109

32 M.'. Reetz, W. Helbig and S.A. Quaiser, in Active Metals - Preparation, Characterization, Application', ed. A Fürstner, VCH, Weinheim, 1995 , p. 279

33 L.D. Burke and B.H. Lee, J. Electroanal. Chem., 1992, 330, 637

34 G. Nguyen Van Huong, C. Hinnen and J. Lecoeur, J. Electroanal. Chem., 1980, 106, 185

35 ' $\Gamma$. Watanabe and H. Gerischer, J.Electroanal. Chern., 1981, 122, 73

$36 \mathrm{~J}$. Desilvestro and M.J. Weavers, J.Electroanal. Chem., 1986, 209, 377

37 R.S. Hutton and D.E. Williams, J. Am. Chem. Soc., 1994, 116, 3453

38 D.W. Kirk, F.R. Foulkes and W.F. Graydon, J. Electrochem. Soc., 1980, 127, 1069

39 H. Angerstein-Kozlowska, B.E. Conway and A. Hamelin, Electrochim. Acta, 1990, 277, 233

40 H. Angerstein-Kozlowska, B.E. Conway, A. Hamelin and L. Stoicoviciu, Electrochim. Acta, 1986, 31, 1051

41 H. Angerstein-Kozlowska, B.E. Conway, A. Hamelin and L. Stoicoviciu, J. Electroanal. Chem., 1987, 228, 429

42 H. Angerstein-Kozlowska, B.E. Conway, B. Barnett and J. Mozota, J. Electroanal. Chem., 1979, 100, 417

43 L.D. Burke and W.A. O'Leary, J. Appl. Electrochem., 1989, 19,758

44 G. Horanyi and E.M. Rizmayer, J. Electroanal. Chem., 1984, 165, 279

45 J.S. Gordon and D.C. Johnson, J. Electroanal. Chem., 1994, 365, 267

46 W. Kautek, M. Sahre and D.M. Soames, Ber Bunsenges. Phys. (.hern., 1995, 99, 667

47 T. Zambelli, J. Winterlin, J. Trost and G. Ert, Science, 1996, 273, 1688

48 L.D. Burke, Platinum Metals Rev., 1994, 38, 166

49 A.Henglein, Ber. Bunsenges. Phys. Chern., 1995, 99, 903

50 F. Parmigiani, E. Kay and P.S. Bagus, J. Electron. Spectrosc. Relat. Phenom., 1990, 50, 39

51 D.W. Suggs and A.J. Bard, J. Am. Chem. Soc., 1994, 116, 10725 